\title{
Experimental Investigations into Abrasive Waterjet Machining of Carbon Fiber Reinforced Plastic
}

\author{
Prasad D. Unde, ${ }^{1}$ M. D. Gayakwad, ${ }^{1}$ N. G. Patil, ${ }^{1}$ R. S. Pawade, ${ }^{2}$ \\ D. G. Thakur, ${ }^{3}$ and P. K. Brahmankar ${ }^{2}$ \\ ${ }^{1}$ Marathwada Institute of Technology, Aurangabad 431028, India \\ ${ }^{2}$ Dr. Babasaheb Ambedkar Technological University, Lonere 402103, India \\ ${ }^{3}$ Defence Institute of Advanced Technology, Pune 411025, India \\ Correspondence should be addressed to N. G. Patil; nileshgpatil@rediffmail.com
}

Received 2 June 2015; Revised 18 August 2015; Accepted 6 September 2015

Academic Editor: Nikhil Gupta

Copyright (C) 2015 Prasad D. Unde et al. This is an open access article distributed under the Creative Commons Attribution License, which permits unrestricted use, distribution, and reproduction in any medium, provided the original work is properly cited.

Abrasive waterjet machining (AWJM) is an emerging machining process in which the material removal takes place due to abrasion. A stream of abrasive particles mixed with filtered water is subjected to the work surface with high velocity. The present study is focused on the experimental research and evaluation of the abrasive waterjet machining process in order to evaluate the technological factors affecting the machining quality of CFRP laminate using response surface methodology. The standoff distance, feed rate, and jet pressure were found to affect kerf taper, delamination, material removal rate, and surface roughness. The material related parameter, orientation of fiber, has been also found to affect the machining performance. The kerf taper was found to be 0.029 for $45^{\circ}$ fiber orientation whereas it was 0.036 and 0.038 for $60^{\circ}$ and $90^{\circ}$, respectively. The material removal rate is $18.95 \mathrm{~mm} / \mathrm{sec}$ for $45^{\circ}$ fiber orientation compared to $18.26 \mathrm{~mm}^{3} / \mathrm{sec}$ for $60^{\circ}$ and $17.4 \mathrm{~mm}^{3} / \mathrm{sec}$ for $90^{\circ}$ fiber orientation. The $R_{a}$ value for $45^{\circ}$ fiber orientation is $4.911 \mu \mathrm{m}$ and for $60^{\circ}$ and $90^{\circ}$ fiber orientation it is $4.927 \mu \mathrm{m}$ and $4.974 \mu \mathrm{m}$, respectively. Delamination factor is found to be more for $45^{\circ}$ fiber orientation, that is, 2.238 , but for $60^{\circ}$ and $90^{\circ}$ it is 2.029 and 2.196 , respectively.

\section{Introduction}

Carbon fibers which are commonly used to reduce the weight of structural components on the aircraft result in improved fuel economy, reduced emissions, and increased load carrying capacity of the aircraft. CFRP also found application in automobile parts like car body, frame, hood, roof, and body panel for bus, propeller shaft, compressed natural gas tank, radiator core support, and chassis. They are also used in sporting goods like ski, bicycle, fishing rods, hockey sticks, badminton rackets, and golf shaft. CFRP proved to be good for environment and energy related applications like wind power blades, tidal power blades, fuel cells, tube trailer tank, battery charging flywheel, and electric cable core. However, some properties of composite laminates like nonhomogeneity, anisotropy, and highly abrasive and hard reinforced fibers make the machining of these laminates difficult $[1,2]$. During machining, kinds of damage such as delamination and fiber pull-out occur which may reduce strength against fatigue, thus degrading the long-term performance of composite laminates [3]. The material delamination is serious issue associated with the machining of these materials $[4,5]$. Carraro et al. [3] reported that voids present in the stacking of laminate may lead to propagation of damage in the laminate during processing. They further mentioned that the intralaminar and interlaminar properties play significant role in development of the damage. It was reported that, in aircraft industry, the rejection of parts due to delamination of material was as high as 60\% [6]. Delamination remains the major challenge in machining of CFRP laminate by using most of the machining processes. Presently, there is no process which gives the complete solution for the delamination of the CFRP material. It has been demonstrated that the performance of AWJM is superior compared to laser machining and waterjet machining as far as delamination is concerned [5, 7]. Also it has been reported that the waterjet cutters are the efficient tools for the machining of the layered composites $[2,5]$. They further added that delamination reduces significantly 
using AWJM. In AWJM, high velocity jet of abrasive slurry is impacted on work surface and it removes the material based on the principle of erosion of the material. AWJM has advantages like high machining versatility, relatively small cutting forces, high flexibility, and no thermal distortion [8]. While comparing with other machining processes like laser cutting and conventional machining process, no heat affected zone on the workpiece is produced [9]. Due to wide applications in aerospace and probable penetration in automotive industry, successful machining of these materials is necessary. Conventional machining is associated with poor surface integrity, laser beam machining leads to severe thermal damage, and wire electrodischarge machining is limited to conductive materials only. Although AWJM is associated with noisy pump and higher operating cost, it appears to show promise in machining of CFRP as compared to laser and WJM $[1,5,10]$. In addition, delamination is significantly reduced in this process $[1,5]$. Besides, like laser beam machining, workpiece thickness is not a limitation in AEJM. Based on the literature, it appeared that although many attempts have been made to study AWJ and AWJM of CFRP, most of the studies have been undertaken on drilling. Therefore, it is necessary to investigate the profile cutting using AWJM. Besides, to the best of our knowledge, there are very few studies on modeling of AWJM of these materials. Therefore, the present study was undertaken to investigate the combination of input process parameters such as jet pressure, standoff distance, feed rate on dimensional accuracy, surface quality, and material removal rate. The effects of fiber orientation of these performance measures have also been studied, especially due to probable applications with different fiber orientation. In addition, empirical models have also been developed for kerf, surface roughness, and materials removal rate using response surface methodology. The scope of this study is, therefore, limited to empirical study of machinability of CFRP using AWJM.

\section{Experimentation}

The machine tool used for experimentation is manufactured by Waterjet Germany Pvt. Ltd. and model number is S3015, a CNC machine with working bed size $3200 \times 1700 \mathrm{~mm}$. The $x$-, $y$-, and $z$-axis travel are $3000 \mathrm{~mm}, 1500 \mathrm{~mm}$, and $200 \mathrm{~mm}$, respectively, with table height $910 \mathrm{~mm}$. The maximum working pressure is $400 \mathrm{MPa}$ which is generated with $37 \mathrm{KW}$ motor. The accuracy and repeatability of the machine are $\pm 0.05 \mathrm{~mm}$ and $\pm 0.03 \mathrm{~mm}$, respectively. The workpiece used is a bidirectional CFRP laminate with size $100 \times 100 \times 8 \mathrm{~mm}$ and with fiber orientation being $45^{\circ}, 60^{\circ}$, and $90^{\circ}$. A carbon fiber is a fibrous carbon material having a micrographite crystal structure made by fibrillation of epoxy resin. The strength to weight ratio for carbon fiber is 2457 with fiber diameter about $7 \mu \mathrm{m}$. The tensile strength of the samples is about $1600 \mathrm{Nmm}^{-2}$.

2.1. Planning of the Experiments. The experimentation is carried out considering the jet pressure, feed rate, standoff distance, and fiber orientation. The jet pressure in AWJM is
TABLE 1: Process parameter levels considered for experimentation.

\begin{tabular}{lccccc}
\hline \multirow{2}{*}{ Parameter } & \multicolumn{5}{c}{ Levels } \\
& -2 & -1 & 0 & +1 & +2 \\
\hline Jet pressure, $\mathrm{MPa}(\mathrm{JP})$ & 80 & 160 & 240 & 320 & 400 \\
Feed rate, $\mathrm{m} / \mathrm{min}(\mathrm{FR})$ & 2 & 4 & 6 & 8 & 10 \\
Standoff distance, $\mathrm{mm}(\mathrm{SoD})$ & 10 & 15 & 20 & 25 & 30 \\
Fiber orientation, degree (OR) & 45 & 45 & 60 & 90 & 90 \\
\hline
\end{tabular}

important parameter as it decides the kinetic energy of the abrasive particles. The greater the jet pressure is, the more the kinetic energy is and the less the deflection of jet is [6]. The jet pressure also decides the MRR in the process. It has been also reported that with an increase in standoff distance the kerf width increases. The feed rate decides the efficiency of the process [11]. The surface roughness increases with increase in feed rate and standoff distance $[12,13]$. However, relatively less study is available about the influence of fiber orientation. The different fiber orientations affect the quality of the cut. It has been reported that the CFRP laminate with $90^{\circ}$ fiber orientation gives superior results for surface roughness [14]. The effect of fiber orientation on surface roughness of the CFRP laminate while trimming using polycrystalline diamond tool is studied reporting that the fiber orientation plays role in deciding the surface roughness [15].

In the present study, the input parameters which have been decided are abrasive waterjet pressure, feed rate, standoff distance, and a material related parameter, that is, fiber orientation. Table 1 shows the levels and range of abovementioned process parameter for the experimentation.

2.2. Response Surface Methodology. Response surface methodology (RSM) is a collection of mathematical and statistical techniques for empirical model building. To reduce the size of experiments without compromising the accuracy, the uniform precision rotatable central composite experimental design (CCD) was used $[16,17]$. In physical experiments, inaccuracy can be due, for example, to measurement errors while, in computer experiments, numerical noise is a result of incomplete convergence of iterative processes, round-off errors, or the discrete representation of continuous physical phenomena. In RSM, the errors are assumed to be random. The application of RSM to design optimization is aimed at reducing the cost of expensive analysis methods and their associated numerical noise.

Table 2 shows the details of response surface experiments.

\section{Results and Discussion}

3.1. Kerf Taper. The kerf taper is an undesirable outcome of any machining process. In the present study, kerf taper was found to be influenced by fiber orientation and standoff distance.

The kerf taper is calculated as [18]

$$
\text { Kerf Taper }=\frac{L_{t}-L_{b}}{2 T},
$$


TABLE 2: Experimental design matrix.

\begin{tabular}{|c|c|c|c|c|}
\hline $\begin{array}{l}\text { Experiment } \\
\text { number }\end{array}$ & $\begin{array}{c}\text { Jet } \\
\text { pressure } \\
{[\mathrm{MPa}]}\end{array}$ & $\begin{array}{l}\text { Feed rate } \\
{[\mathrm{m} / \mathrm{min}]}\end{array}$ & $\begin{array}{c}\text { Standoff } \\
\text { distance } \\
{[\mathrm{mm}]}\end{array}$ & $\begin{array}{c}\text { Fiber } \\
\text { orientation } \\
\text { [degree] }\end{array}$ \\
\hline 1 & 160 & 4 & 15 & 45 \\
\hline 2 & 320 & 4 & 15 & 45 \\
\hline 3 & 160 & 8 & 15 & 45 \\
\hline 4 & 320 & 8 & 15 & 45 \\
\hline 5 & 160 & 4 & 25 & 45 \\
\hline 6 & 320 & 4 & 25 & 45 \\
\hline 7 & 160 & 8 & 25 & 45 \\
\hline 8 & 320 & 8 & 25 & 45 \\
\hline 9 & 160 & 4 & 15 & 90 \\
\hline 10 & 320 & 4 & 15 & 90 \\
\hline 11 & 160 & 8 & 15 & 90 \\
\hline 12 & 320 & 8 & 15 & 90 \\
\hline 13 & 160 & 4 & 25 & 90 \\
\hline 14 & 320 & 4 & 25 & 90 \\
\hline 15 & 160 & 8 & 25 & 90 \\
\hline 16 & 320 & 8 & 25 & 90 \\
\hline 17 & 80 & 6 & 20 & 60 \\
\hline 18 & 400 & 6 & 20 & 60 \\
\hline 19 & 240 & 2 & 20 & 60 \\
\hline 20 & 240 & 10 & 20 & 60 \\
\hline 21 & 240 & 6 & 10 & 60 \\
\hline 22 & 240 & 6 & 30 & 60 \\
\hline 23 & 240 & 6 & 20 & 45 \\
\hline 24 & 240 & 6 & 20 & 90 \\
\hline 25 & 240 & 6 & 20 & 60 \\
\hline 26 & 240 & 6 & 20 & 60 \\
\hline 27 & 240 & 6 & 20 & 60 \\
\hline 28 & 240 & 6 & 20 & 60 \\
\hline 29 & 240 & 6 & 20 & 60 \\
\hline 30 & 240 & 6 & 20 & 60 \\
\hline
\end{tabular}

where $L_{t}$ is kerf width at top side; $L_{b}$ is kerf width at bottom side; $T$ is thickness of the laminate; unit for kerf taper is $\mathrm{mm} / \mathrm{mm}$.

Based on response surface design of experiments empirical model for kerf taper has been developed. The model is presented as

$$
\begin{aligned}
\text { Kerf Taper }= & 1.7-0.00093 \mathrm{JP}-0.383 \mathrm{~S}+0.356 \mathrm{OR} \\
& -0.000043 \mathrm{JP} \text { OR. }
\end{aligned}
$$

The correlation coefficient $(r)$ is 0.80 .

The most significant process parameter was found to be fiber orientation. For $45^{\circ}$ fiber orientation it gives best results. Compared to $60^{\circ}$ and $90^{\circ}$ fiber orientation, kerf taper was found to reduce while machining of workpiece with $45^{\circ}$ fiber orientation. This might be attributed to less volume fraction of reinforcement in this material.

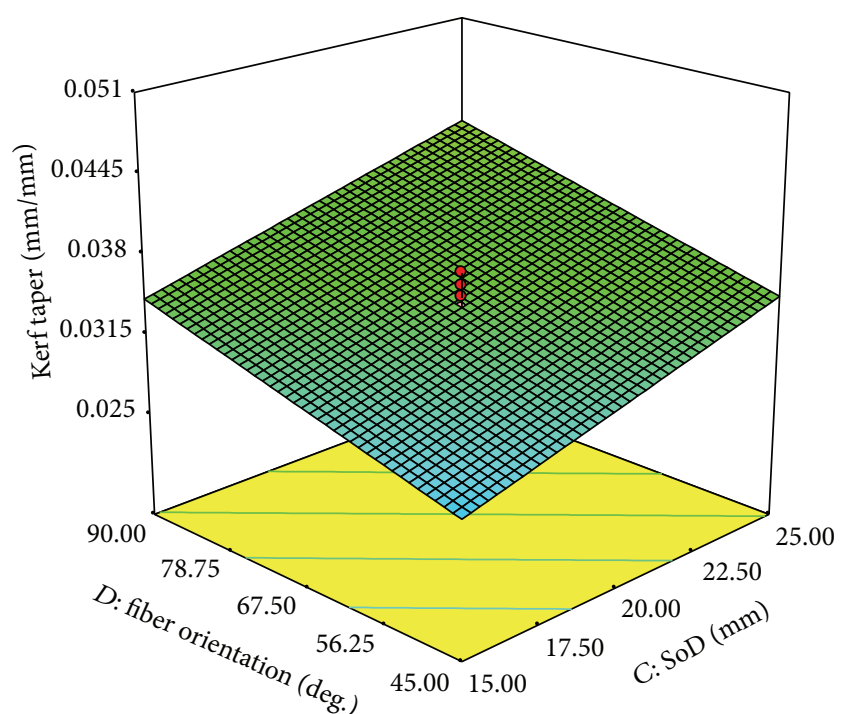

FIGURE 1: Kerf taper versus fiber orientation and standoff distance.

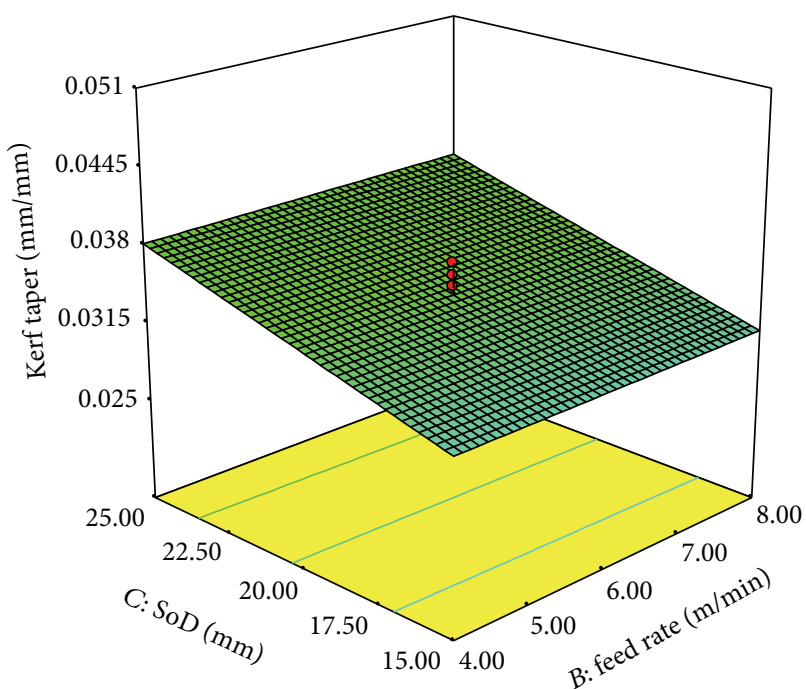

FIgURE 2: Kerf taper versus standoff distance and feed rate.

The kerf taper was found to increase with standoff distance. This can be attributed to the reduced cutting ability of the abrasives when moving from the top to the bottom. The abrasive particles retard the cutting ability when moving from top surface to bottom surface. Figures 1 and 2 show the effect of fiber orientation and standoff distance on kerf taper. Kerf taper was found to reduce with increased jet pressure as shown in Figures 3 and 4. This can be attributed to increased cutting ability of the abrasive particles at greater jet pressure due to higher kinetic energy.

Findings in the past $[5,7]$ are in agreement with the present observations. The feed rate has no effect on the kerf taper. Thus, the jet pressure, fiber orientation, and standoff distance decide the taper in AWJM process. 


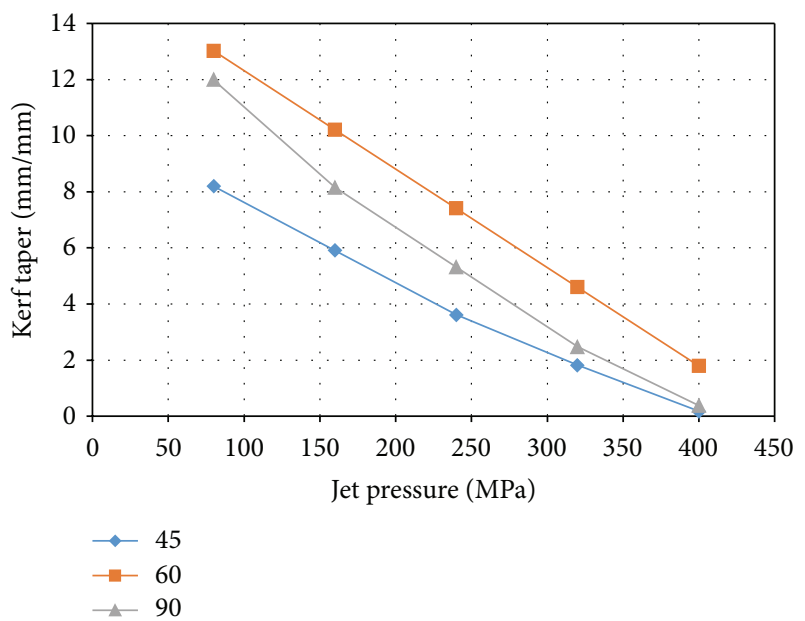

FIGURE 3: Jet pressure versus kerf taper.

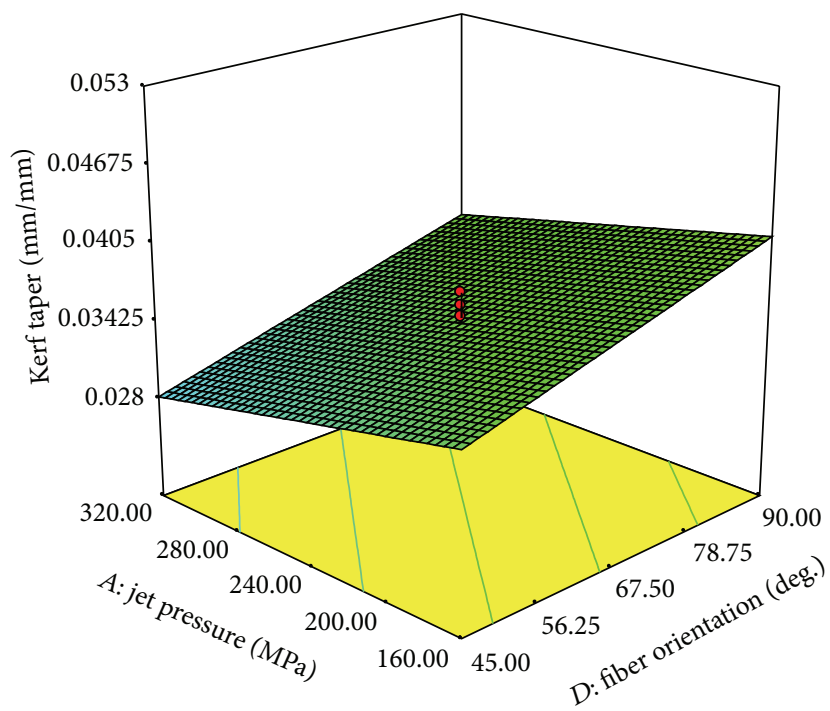

FIGURE 4: Kerf taper versus jet pressure and fiber orientation.

3.2. Delamination Factor. Delamination is the major defect found in machining of the composite materials. In CFRP laminate, the delamination has been observed on both sides of the laminate, that is, top and bottom side. It has been reported that the delamination is initiated by the shock wave generated by the jet in AWJM [5]. Therefore delamination is more on top side as compared to the bottom side. Figures 5,6 , and 7 show that delamination is more on top side as compared to bottom side. When the abrasive particles reach the top surface they possess more energy to cut the material and then they continuously lose some part of the energy during propagation of the jet. Figure 8 shows surface plot of delamination versus standoff distance. As the standoff distance increases the jet gets diverge and the cutting area increases with an increase in jet diversion.

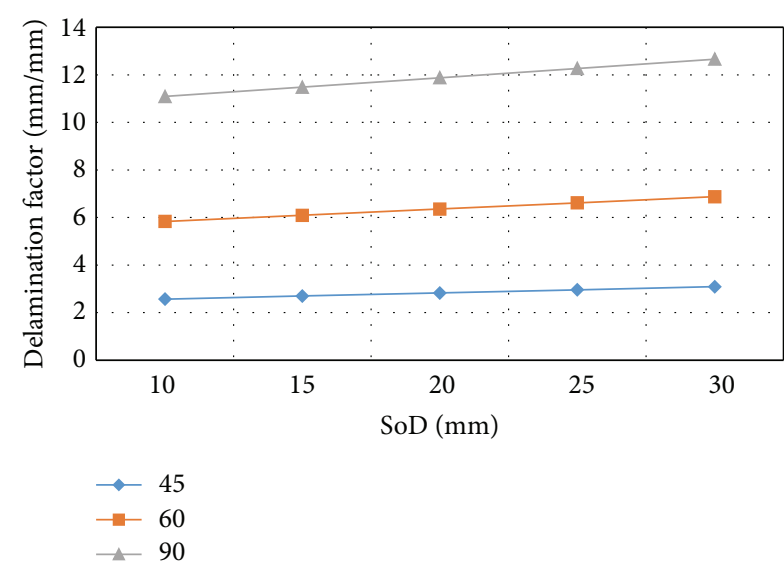

Figure 5: SoD versus top DF.

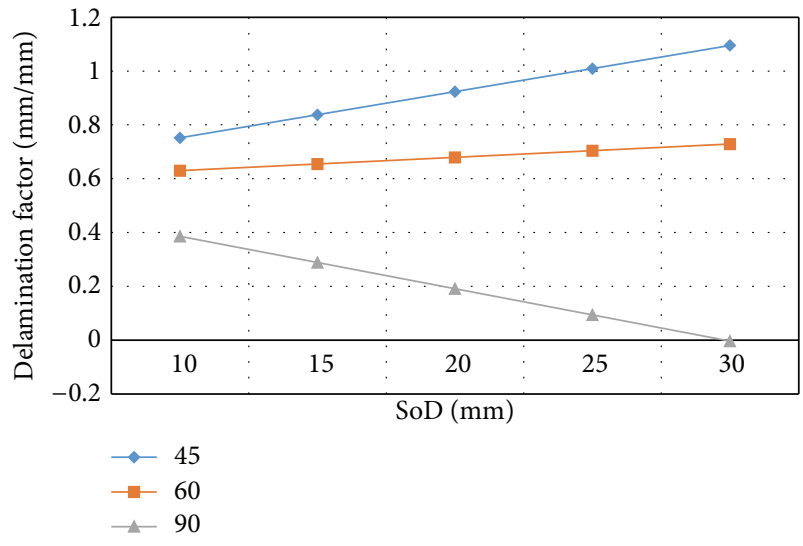

FIGURE 6: SoD versus bottom DF.

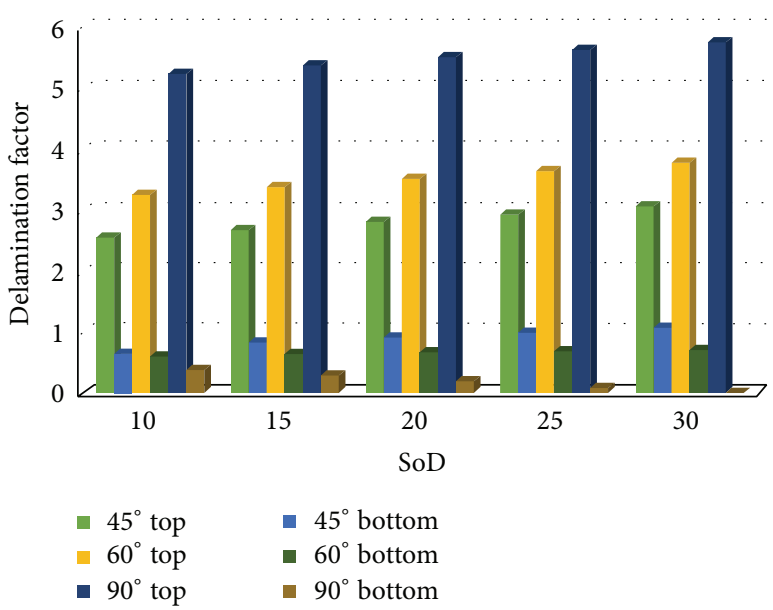

Figure 7: Comparison of delamination factor.

The delamination factor is calculated as [19]

$$
\text { Delamination Factor }=\frac{W_{d}}{W_{o}},
$$

where $W_{d}$ is maximum damaged width and $W_{o}$ is original width of cut. 


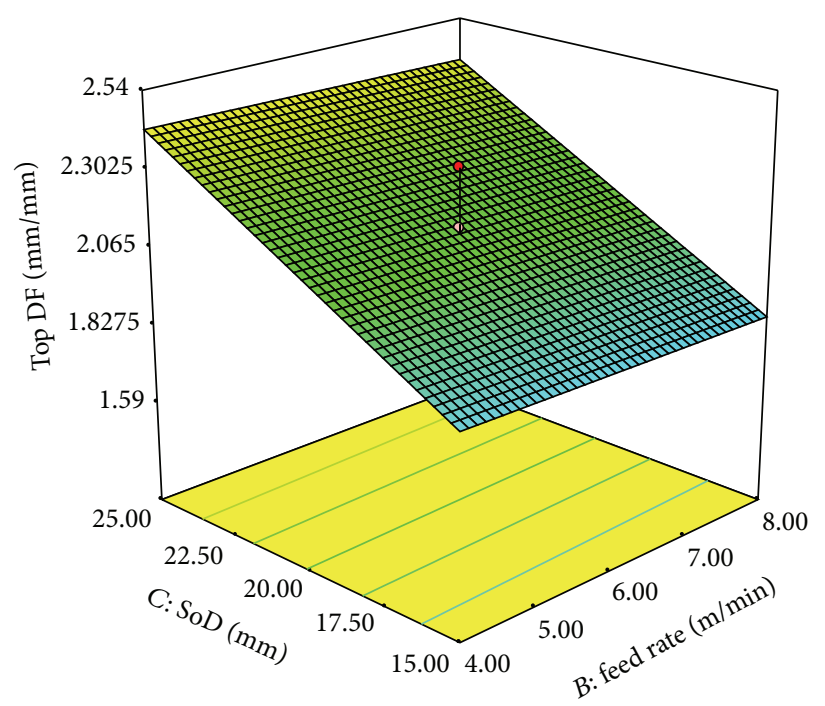

Figure 8: Delamination on top side versus standoff distance and feed rate.

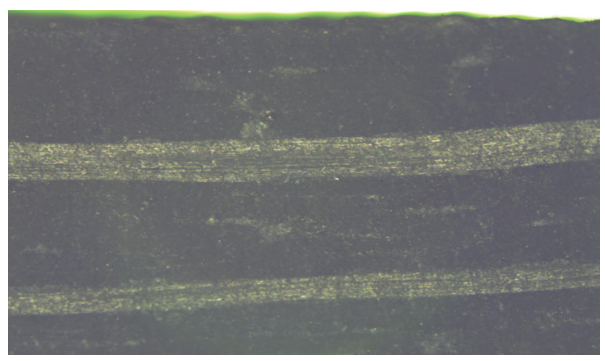

(a) Optical microimage

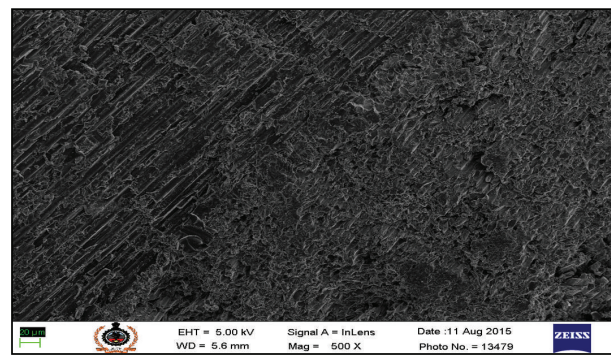

(b) SEM image

FIgURE 9: Machined surface.

Based on results of experiments, empirical models for top and bottom delamination factor have been developed as

$$
\begin{aligned}
\text { Top DF } & =1.41+0.0261 \mathrm{~S}+0.000443 \mathrm{OR}^{2}, \\
\text { Bottom DF } & =0.58+0.0538 \mathrm{~S}-0.000814 \mathrm{~S} \mathrm{OR} .
\end{aligned}
$$

The correlation coefficients $(r)$ are 0.86 and 0.81 , respectively, for top and bottom side.

The standoff distance has been found to significantly influence the delamination on the top as well as bottom side of the CFRP laminate. The parameters like jet pressure and feed rate decide the kinetic energy and the cutting time for the process. But the standoff distance decides the area of cutting which increases or decreases the impact area. Topography of the machined surface is as shown in Figure 9.

3.3. Material Removal Rate (MRR). The material removal rate in any machining process is imperative parameter to decide the efficiency of the process. The feed rate was found to be the most significant parameter. MRR was found to improve with increased feed rate, Figure 10. The surge in feed rate reduces the time required to complete the process. The feed rate decides the time required to complete the process.
Material removal rate is calculated by using [20]

$$
\operatorname{MRR}=\frac{1}{2} \frac{\left(L_{t}+L_{b}\right) T L_{c}}{t},
$$

where $L_{t}$ is kerf width at top side, $L_{b}$ is kerf width at bottom side, $L_{c}$ is length of cut, $T$ is thickness of the laminate, $t$ is time required to perform operation, and unit is $\mathrm{mm}^{3} / \mathrm{sec}$.

A model has been developed by using RSM experiments:

$$
\begin{aligned}
\mathrm{MRR}= & 11.5-0.53 \mathrm{FR}-0.518 \mathrm{~S}+0.2688 \mathrm{FR}^{2} \\
& +0.000261 \mathrm{JPS}-0.00938 \mathrm{SOR}^{2} .
\end{aligned}
$$

The correlation coefficient $(r)$ is 0.96 .

Figure 11 shows that, along with feed rate and standoff distance, MRR was found to be greater at higher jet pressure and at $45^{\circ}$ fiber orientation. The CFRP material with $45^{\circ}$ has less interaction of abrasive jet with fiber as compared to $60^{\circ}$ and $90^{\circ}$. Polymer resin is easy to cut as compared to fibers and therefore the $45^{\circ}$ fiber orientation gives better MRR than the $60^{\circ}$ and $90^{\circ}$. Also with increased jet pressure the kinetic energy of the abrasive particles increases. The higher kinetic energy increases the cutting ability of the abrasive particles which helps to remove more volume of material. MRR was 


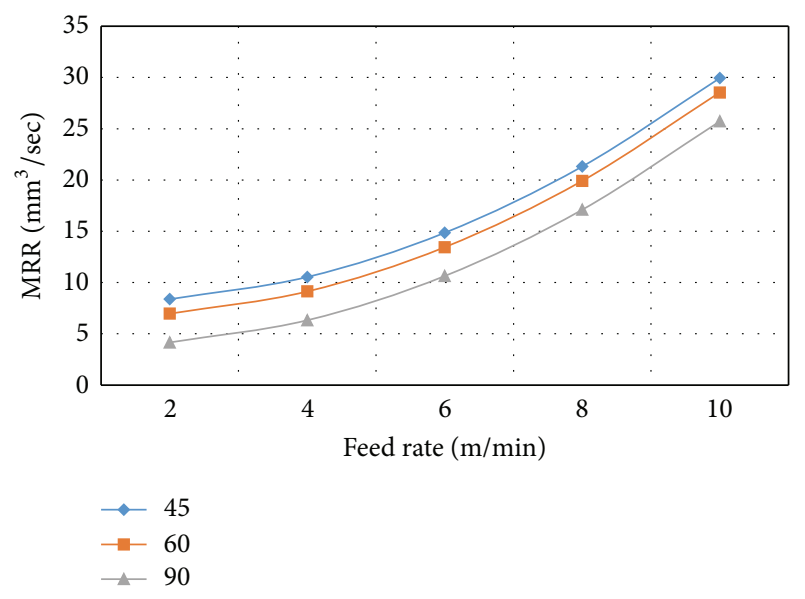

FIGURE 10: Feed rate versus MRR.

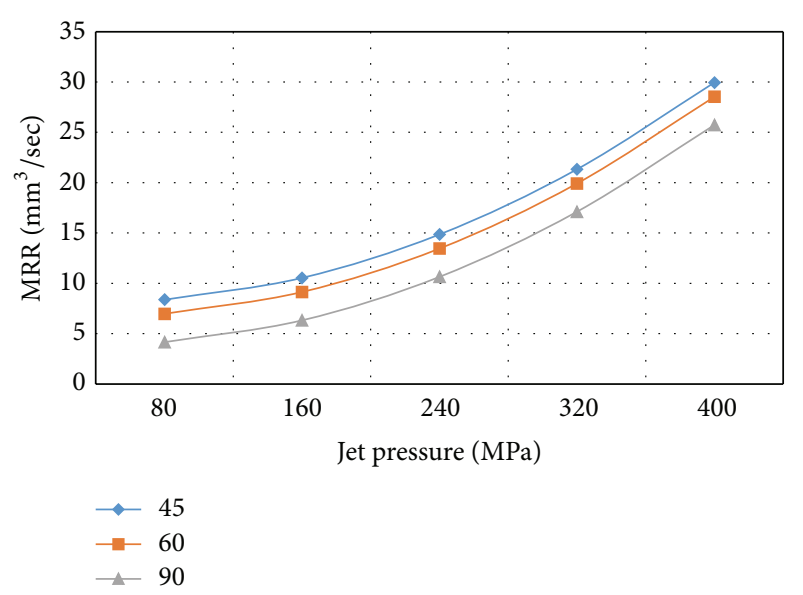

FIGURE 11: Jet pressure versus MRR.

found to increase with increased standoff distance, Figure 12. This can be attributed to divergence in jet and low kinetic energy of the abrasive particles due to more distance between the jet and the workpiece.

3.4. Surface Roughness. The AWJM parameters have been found to influence the surface roughness measured in terms of $R_{a}, R_{p}$, and $R_{z}$. However, values like $R_{v}, R_{k u}, R_{s k}$, and $R_{s m}$ remain unaffected. Figures 13,14 , and 15 show that $R_{a}$ value increases with increase in feed rate and SoD. The feed rate influences the time required for the cutting of the material. With increase in feed rate the abrasive particle gets less time to cut the material and new particles arrive in cutting region. With increase in feed rate the abrasive particles get less time to cut the material though particles possess more or less cutting energy. This increases the surface roughness. As standoff distance increases the distance to be traveled by the abrasive particles also increases. With increase in distance, the sharp cutting of the material is not possible which might be effect of reduced cutting ability of the abrasive particles. Therefore, as standoff distance increases the abrasive particles lose cutting ability during traveling owing to distance traveled

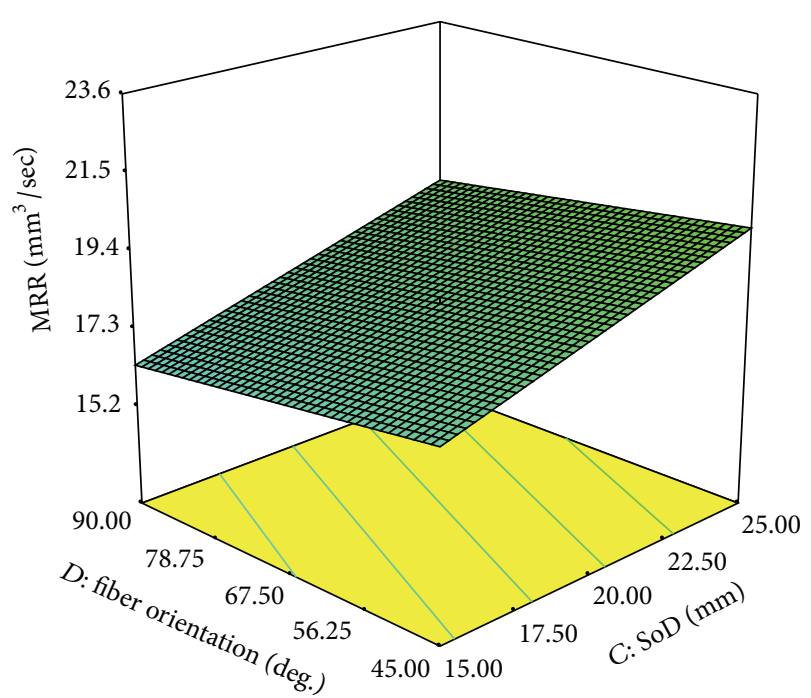

FIGURE 12: MRR versus fiber orientation and SoD.

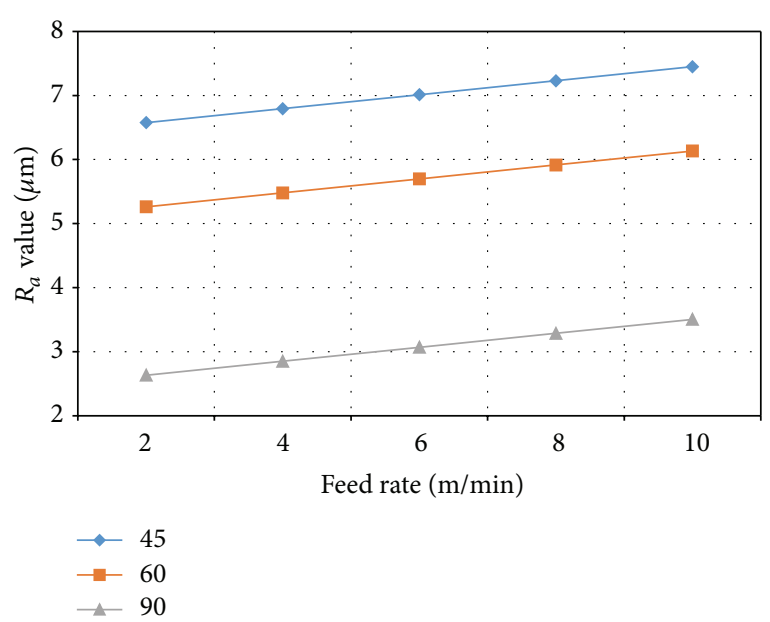

FIgURE 13: Feed rate versus $R_{a}$.

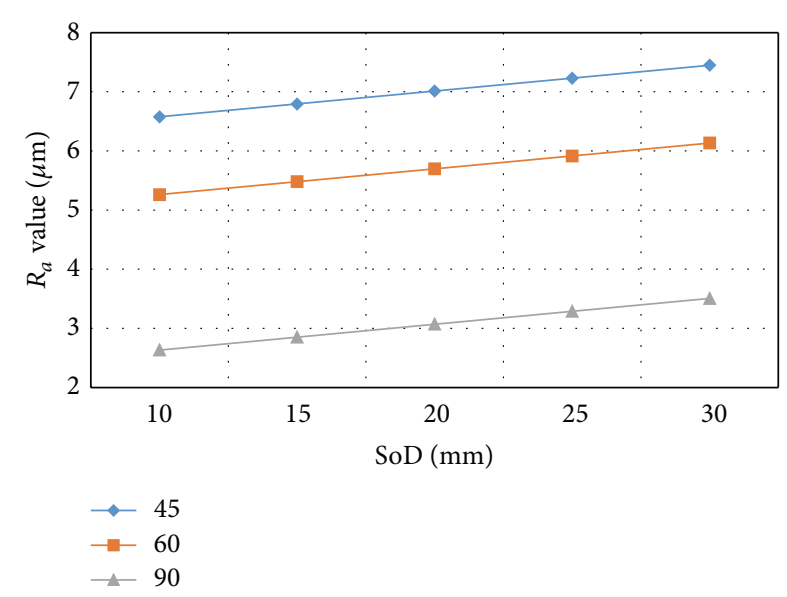

FIgURE 14: SoD versus $R_{a}$. 


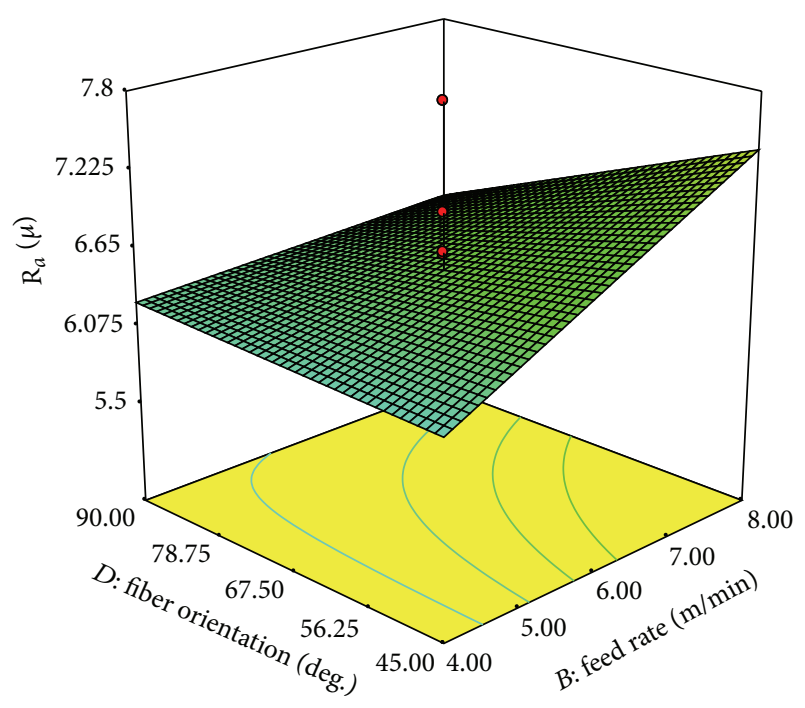

FIGURE 15: $R_{a}$ versus fiber orientation and feed rate.

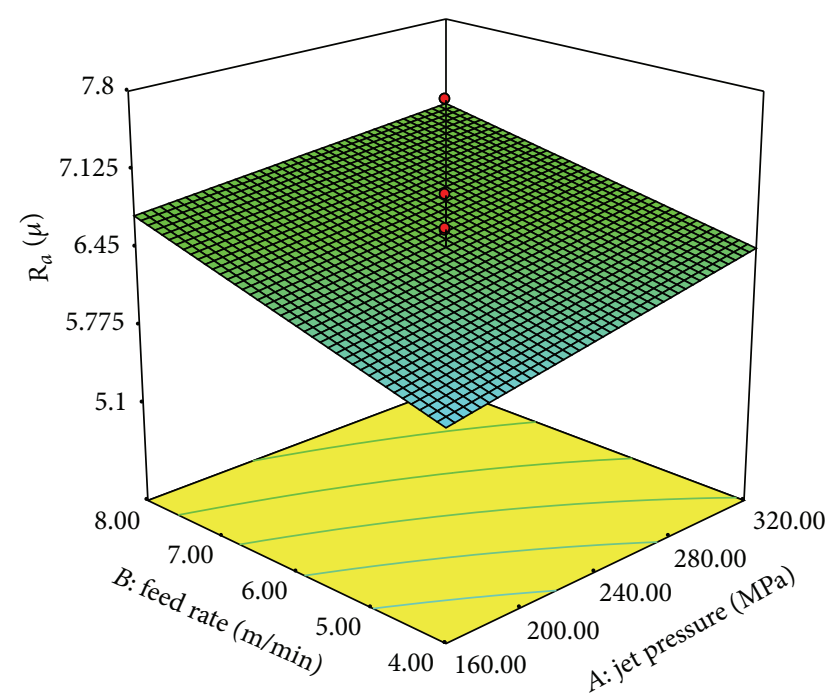

FIGURE 16: $R_{a}$ versus feed rate and jet pressure.

and the intercollision between particles. This is in agreement with the findings of previous investigations $[7,8]$.

Empirical models for $R_{a}, R_{p}$, and $R_{z}$ value have been developed using RSM experiments as

$$
\begin{aligned}
R_{a}= & 10.30-0.206 \mathrm{FR}-0.0876 \mathrm{OR}+0.0315 \mathrm{FR} \mathrm{S}, \\
R_{p}= & 27.31-0.305 \mathrm{OR}-0.000001 \mathrm{JP}^{2}+0.00254 \mathrm{OR}^{2} \\
& -0.00649 \mathrm{~S} \mathrm{OR}, \\
R_{z}= & 105.4-1.268 \mathrm{OR}-0.000002 \mathrm{JP}^{2}+0.00894 \mathrm{OR}^{2} \\
& +0.2137 \mathrm{FR} \mathrm{S} .
\end{aligned}
$$

The correlation coefficients for $R_{a}, R_{p}$, and $R_{z}$ value are 0.85 , 0.87 , and 0.85 , respectively.

The jet pressure and the fiber orientation also influence the surface roughness of the component, Figures 16 and 17.

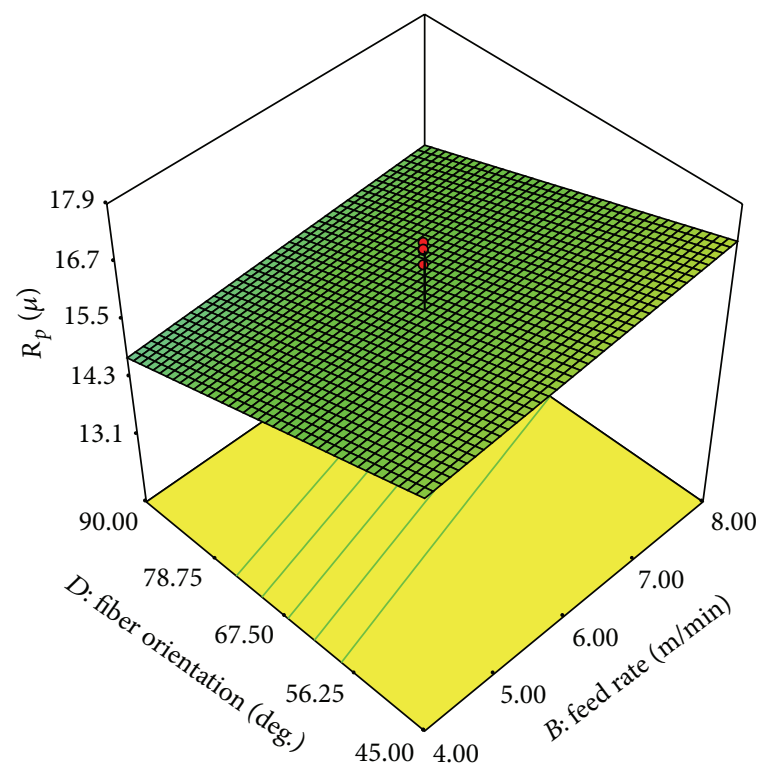

FIGURE 17: $R_{p}$ versus fiber orientation and feed rate.

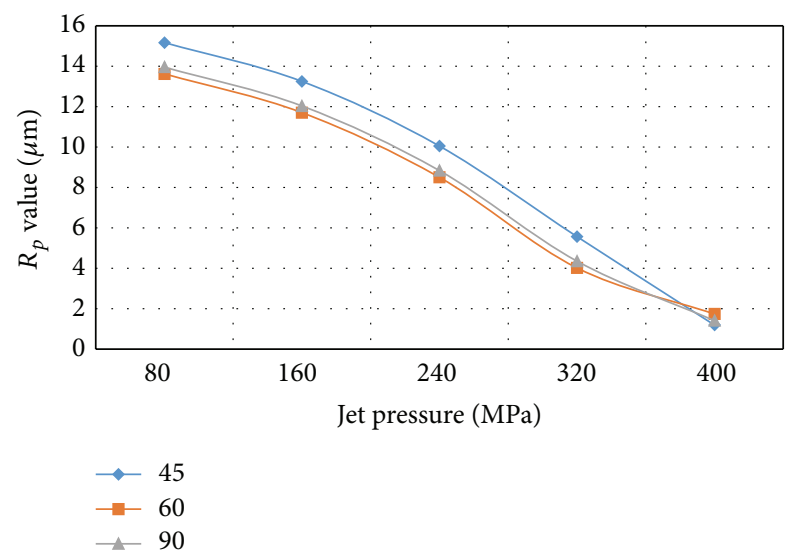

FIGURE 18: Jet pressure versus $R_{p}$.

Figures 18 and 19 show that as the Jet pressure increases the $R_{a}, R_{p}$, and $R_{z}$ value decease, because, with increase in jet pressure, the cutting ability of the abrasive particles increases. Stoic et al. also recommended increase of jet pressure and reduced feed rate to improve the surface finish [13]. It has been found that the fiber orientation also plays important role in deciding the surface roughness. The roughness values are higher for the $45^{\circ}$ fiber orientation as compared to $60^{\circ}$ and $90^{\circ}$. For $45^{\circ}$ and $60^{\circ}$ fiber orientation, the shear plane is elliptical and for $90^{\circ}$ it is circular. Figure 20 shows the jet direction and shear plane for different fiber orientations. Sharp and clean cuts are possible with $90^{\circ}$ orientation. This might be attributed to greater resistance offered by the fibers at $45^{\circ}$ and $60^{\circ}$ orientation. The greater resistance could be due to large shear area at $45^{\circ}$ and $60^{\circ}$ compared to $90^{\circ}$. In $45^{\circ}$ fiber orientation the shear plane area is more as compared to $60^{\circ}$ and $90^{\circ}$ due to reduction in shear angle. As the shear angle 
TABLE 3: Results of experiments.

\begin{tabular}{|c|c|c|c|c|c|c|c|}
\hline Orientation & $\begin{array}{l}\text { Kerf taper } \\
\mathrm{mm} / \mathrm{mm}\end{array}$ & $\begin{array}{l}\text { Top delamination factor } \\
\mathrm{mm} / \mathrm{mm}\end{array}$ & $\begin{array}{l}\text { Bottom delamination factor } \\
\mathrm{mm} / \mathrm{mm}\end{array}$ & $\begin{array}{c}\text { Material removal rate } \\
\mathrm{mm}^{3} / \mathrm{sec}\end{array}$ & $\begin{array}{c}R_{a} \text { value } \\
\mu \mathrm{m}\end{array}$ & $\begin{array}{c}R_{p} \text { value } \\
\mu \mathrm{m}\end{array}$ & $\begin{array}{c}R_{z} \text { value } \\
\mu \mathrm{m} \\
\end{array}$ \\
\hline \multirow{5}{*}{45} & 8.198 & 2.568075 & 0.7517 & 8.3782 & 6.576 & 15.168 & 77.9855 \\
\hline & 5.906 & 2.698575 & 0.83755 & 10.5438 & 6.794 & 13.248 & 74.1455 \\
\hline & 3.614 & 2.829075 & 0.9234 & 14.8598 & 7.012 & 10.048 & 67.7455 \\
\hline & 1.822 & 2.959575 & 1.00925 & 21.3262 & 7.23 & 5.568 & 58.7855 \\
\hline & 0.17 & 3.090075 & 1.0951 & 29.943 & 7.448 & 1.192 & 47.2655 \\
\hline \multirow{5}{*}{60} & 13.022 & 3.2658 & 0.6296 & 6.9712 & 5.262 & 13.62 & 73.046 \\
\hline & 10.214 & 3.3963 & 0.6544 & 9.1368 & 5.48 & 11.7 & 69.206 \\
\hline & 7.406 & 3.5268 & 0.6792 & 13.4528 & 5.698 & 8.5 & 62.806 \\
\hline & 4.598 & 3.6573 & 0.704 & 19.9192 & 5.916 & 4.02 & 53.846 \\
\hline & 1.79 & 3.7878 & 0.7288 & 28.536 & 6.134 & 1.74 & 42.326 \\
\hline \multirow{5}{*}{90} & 11.99 & 5.2593 & 0.3854 & 4.1572 & 2.634 & 13.953 & 75.236 \\
\hline & 8.15 & 5.3898 & 0.2881 & 6.3228 & 2.852 & 12.033 & 71.396 \\
\hline & 5.31 & 5.5203 & 0.1908 & 10.6388 & 3.07 & 8.833 & 64.996 \\
\hline & 2.47 & 5.6508 & 0.0935 & 17.1052 & 3.288 & 4.353 & 56.036 \\
\hline & 0.37 & 5.7813 & 0.0038 & 25.722 & 3.506 & 1.407 & 44.516 \\
\hline
\end{tabular}

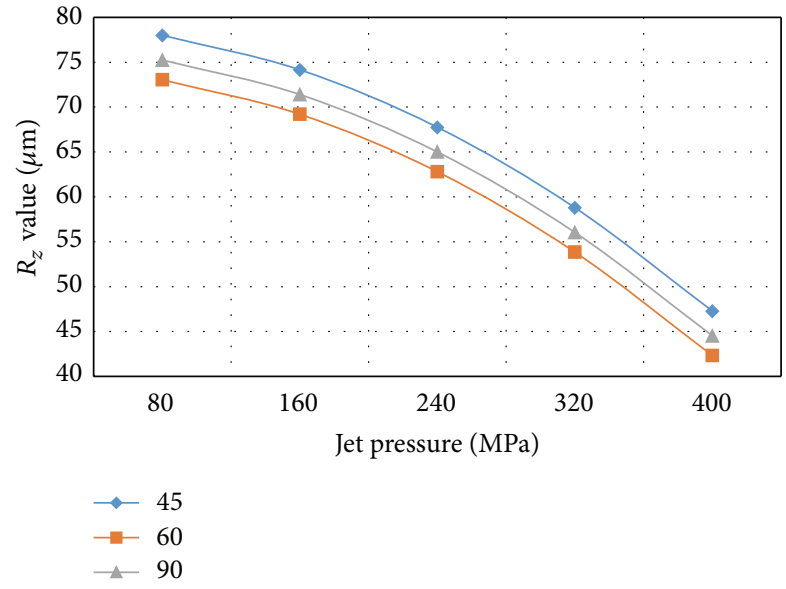

Figure 19: Jet pressure versus $R_{z}$.

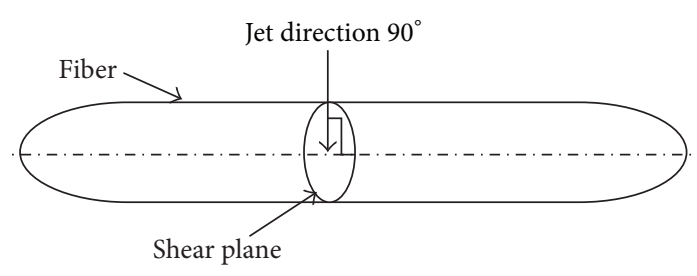

Figure 20: Impact of jet on the fiber.

decreases, the shear plane becomes more elliptical which results in increase in area to be cut.

\section{Conclusions}

In cutting of CFRP laminate using AWJM, various process parameters have influence on the performance measures. The standoff distance and feed rate have been found to show significant influence on the kerf taper, delamination factor, and the MRR. The fiber orientation and jet pressure affect the surface roughness of the cut. The laminate with $45^{\circ}$ fiber orientation gives superior results as compared to $60^{\circ}$ and $90^{\circ}$.

(i) The laminate with $45^{\circ}$ fiber orientation shows kerf taper 0.029 while $60^{\circ}$ and $90^{\circ}$ show 0.036 and 0.038 , respectively.

(ii) Also the laminate with $45^{\circ}$ fiber orientation shows greater MRR, that is, $18.95 \mathrm{~mm}^{3} / \mathrm{sec}$ as compared to $60^{\circ}$ and $90^{\circ}$, that is, $18.26 \mathrm{~mm}^{3} / \mathrm{sec}$ and $17.4 \mathrm{~mm}^{3} / \mathrm{sec}$, respectively.

(iii) The delamination factor and $R_{a}$ value for the laminate with fiber orientation 45 are about 2.239 and 6.967, respectively, which is more as compared to $60^{\circ}$ and $90^{\circ}$.

The fiber orientation is slightly unheeded part in composite machining and there is no significant literature available to study the effect of fiber orientation; we hope that this study will contribute in this concern. It is recommended that, in AWJM, higher jet pressure, less standoff distance, and moderate feed rate will give desirable results.

\section{Appendix}

See Table 3.

\section{Conflict of Interests}

The authors have no conflict of interests to declare.

\section{Acknowledgments}

The authors would like to thank Indutech Composites Tech. Pvt. Ltd., Baroda, for supplying the CFRP material and Sasa 
Engineering, Pune, for providing the machining facilities during the experimentation work.

\section{References}

[1] D. K. Shanmugam, F. L. Chen, E. Siores, and M. Brandt, "Comparative study of jetting machining technologies over laser machining technology for cutting composite materials," Composite Structures, vol. 57, no. 1-4, pp. 289-296, 2002.

[2] D. Babu Rao, D. Baskey, and R. S. Rawat, "Water jet cutter: an efficient tool for composite product development," in Proceedings of the National Conference on Scientific Achievements of SC \& ST Scientists \& Technologists, pp. 104-107, Bangalore, India, April 2009.

[3] P. A. Carraro, L. Maragoni, and M. Quaresimin, "Influence of manufacturing induced defects on damage initiation and propagation in carbon/epoxy NCF laminates," Advanced Manufacturing: Polymer \& Composites Science, vol. 1, no. 1, pp. 44-53, 2015.

[4] V. Mutavgjic, Z. Jurkovic, M. Franulovic, and M. Sekulic, "Experimental investigation of surface roughness obtained by abrasive water jet machining," in Proceedings of the 15th International Research/Expert Conference Trends in the Development of Machinery and Associated Technology (TMT '11), pp. 73-76, Prague, Czech Republic, September 2011.

[5] D. K. Shanmugam, T. Nguyen, and J. Wang, "A study of delamination on graphite/epoxy composites in abrasive waterjet machining," Composites A: Applied Science and Manufacturing, vol. 39, no. 6, pp. 923-929, 2008.

[6] T. U. Siddiqui, M. Shukla, and P. B. Tambe, "Comparative investigation of abrasive waterjet cut kerf quality characteristics for aramid, glass and carbon fiber reinforced composites used in transport aircraft applications," in Proceedings of the American WJTA Conference and Expo, pp. 53-68, Houston, Tex, USA, August 2009.

[7] M. A. Azmir and A. K. Ahsan, "Investigation on glass/epoxy composite surfaces machined by abrasive water jet machining," Journal of Materials Processing Technology, vol. 198, no. 1-3, pp. 122-128, 2008.

[8] S. Libuse, L. Imrich, K. Jana, and S. Oldrich, Waterjet Cutting and Surface Quality Nonconventional Technologies Review, Romanian Association of Nonconventional Technologies, Bucharest, Romania, 2013.

[9] M. Ramulu and D. Arola, "Water jet and abrasive water jet cutting of unidirectional graphite/epoxy composite," Composites, vol. 24, no. 4, pp. 299-308, 1993.

[10] H. Ho-Cheng, "A failure analysis of water jet drilling in composite laminates," International Journal of Machine Tools and Manufacture, vol. 30, no. 3, pp. 423-429, 1990.

[11] B. Chandra and J. Singh, "A study of effect of process parameters of abrasive jet machining," International Journal of Engineering Science and Technology, vol. 3, pp. 504-513, 2011.

[12] J. Wang, "A machinability study of polymer matrix composites using abrasive waterjet cutting technology," Journal of Materials Processing Technology, vol. 94, no. 1, pp. 30-35, 1999.

[13] A. Stoić, M. Duspara, B. Kosec, M. Stoić, and I. Samardžić, "Application of water jet for cutting polymer materials," Metalurgija, vol. 52, no. 2, pp. 255-258, 2013.

[14] M. Hagino and T. Inoue, "Effect of carbon fiber orientation and helix angle on CFRP cutting characteristics by end-milling," International Journal of Automation Technology, vol. 7, no. 3, pp. 292-299, 2013.
[15] J. François Chatelain, "Effect of ply orientation on roughness for the trimming process of CFRP laminates," World Academy of Science, Engineering and Technology, vol. 6, pp. 988-994, 2012.

[16] N. G. Patil, A. Asem, R. S. Pawade, D. G. Thakur, and P. K. Brahmankar, "Comparative study of high speed machining of Inconel 718 in dry condition and by using compressed cold carbon dioxide gas as coolant," Procedia CIRP, vol. 24, pp. 8691, 2014.

[17] R. H. Myers, D. C. Montgomery, and C. M. Anderson-Cook, Response Surface Methodology: Process And Product Optimization Using Designed Experiments, John Wiley \& Sons, New York, NY, USA, 1996.

[18] M. A. Azmir and A. K. Ahsan, "A study of abrasive water jet machining process on glass/epoxy composite laminate," Journal of Materials Processing Technology, vol. 209, no. 20, pp. 61686173, 2009.

[19] D. F. Liu, Y. J. Tang, and W. L. Cong, "A review of mechanical drilling for composite laminates," Composite Structures, vol. 94, no. 4, pp. 1265-1279, 2012.

[20] M. M. Korat and G. D. Acharya, "A review on current research and development in abrasive waterjet machining," International Journal of Engineering Research and Applications, vol. 4, no. 1, pp. 423-432, 2014. 

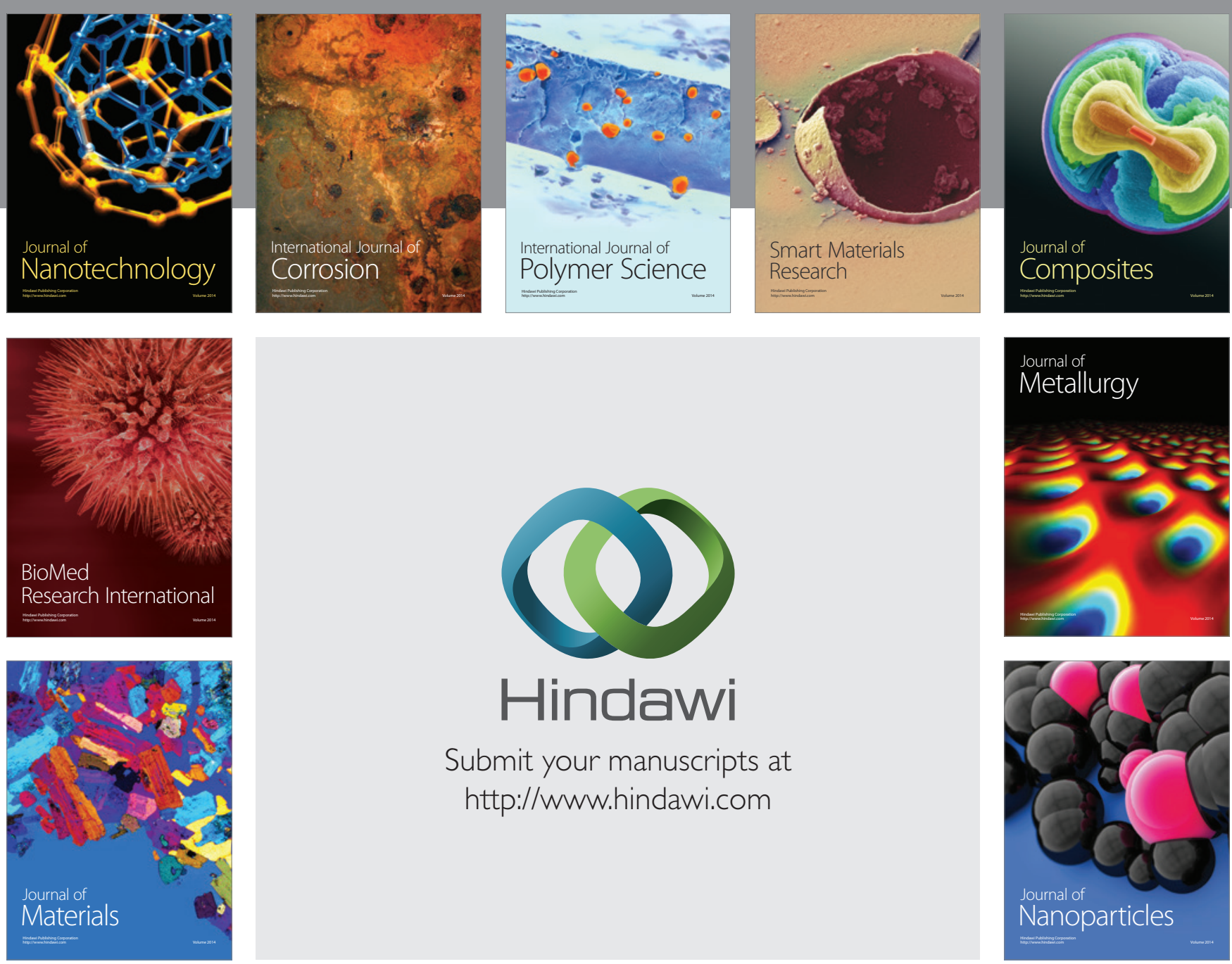

Submit your manuscripts at http://www.hindawi.com
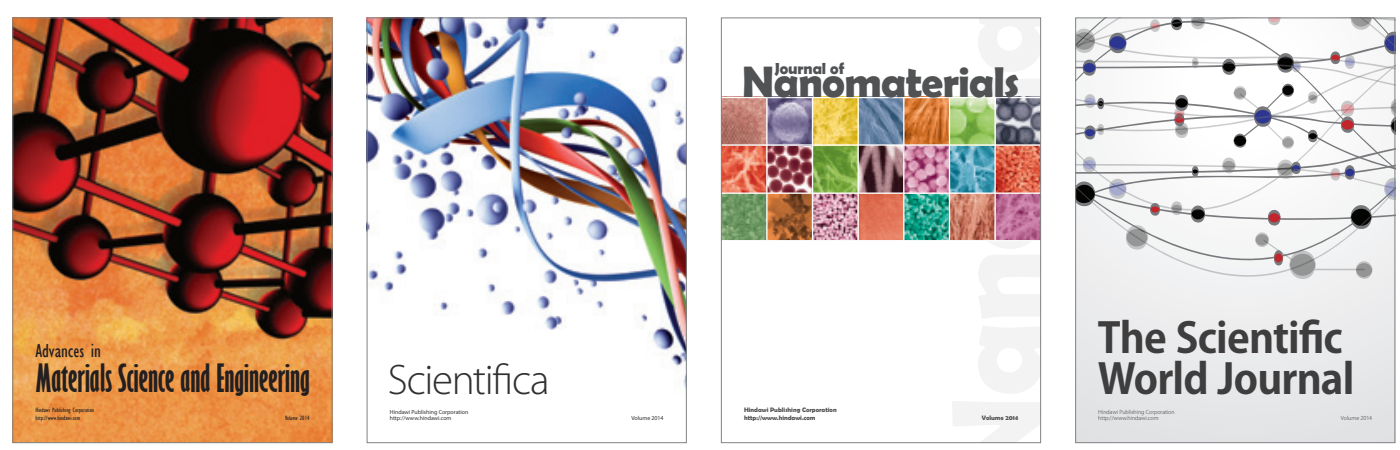

\section{The Scientific World Journal}
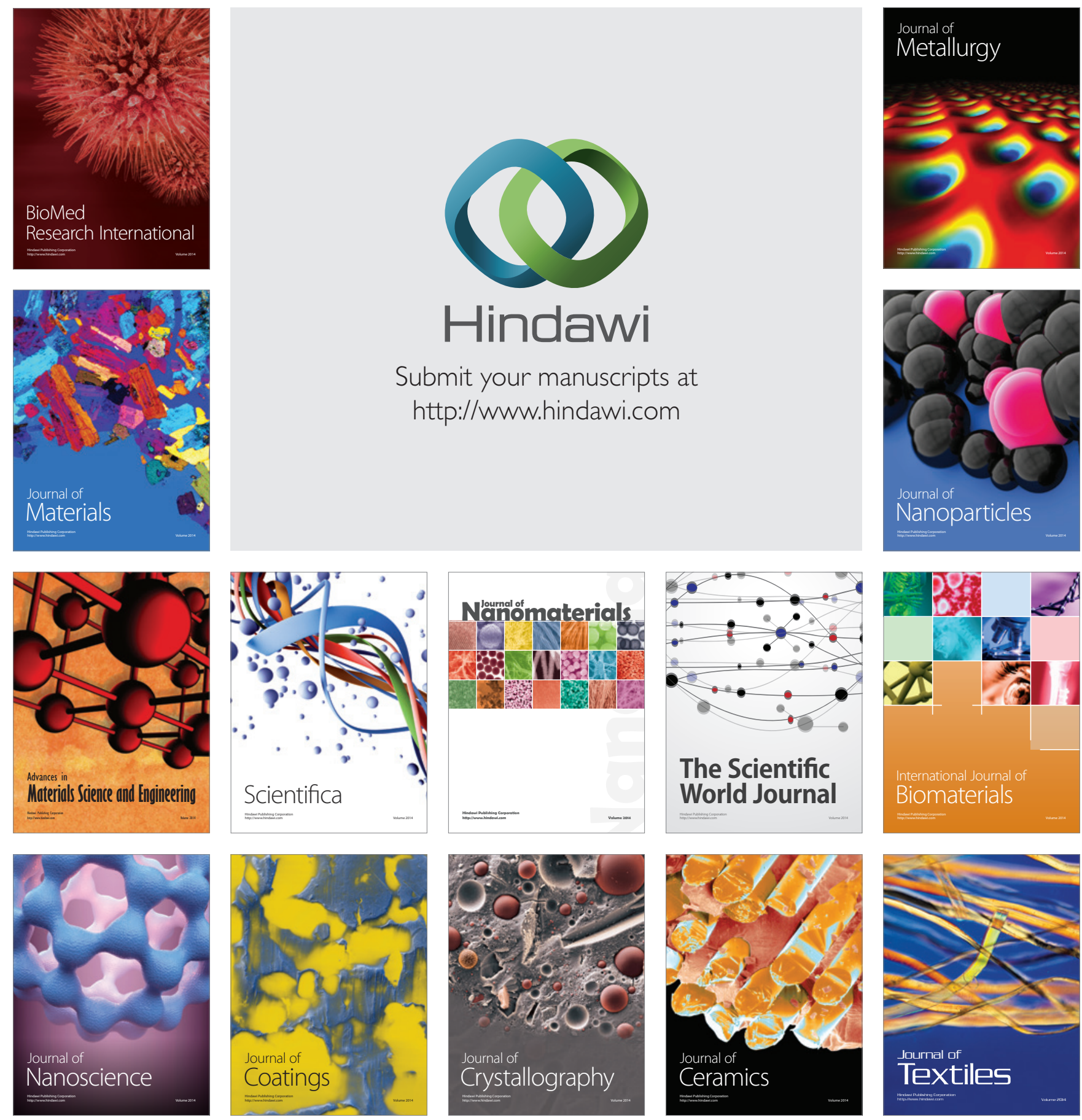